\title{
Developing a Generalized Combined Model for Gas-liquid Two-phase Flow Pressure Drop in Elbow Bends
}

\author{
N. Z. AUNG ${ }^{1 *}$ AND T. YUWONO ${ }^{2}$
}

\begin{abstract}
In this work, a generalized combined model was proposed for prediction of two-phase flow pressure drop in elbow bends. In this proposed model, restriction, frictional and elevational losses were considered separately. The frictional and static losses were approached by using Lockhart Martinelli correlation. This model was tested to predict the pressure drop across the elbows with inside diameter of $0.036 \mathrm{~m}$ and $\mathrm{R} / \mathrm{D}=0.6,2.5$. The superficial liquid velocity was varied in the range of $0.3 \sim 1.1 \mathrm{~m} / \mathrm{s}$ and volumetric gas quality was varied from $0.02 \sim 0.3$. The results from this model had good predictions with a maximum error of $\pm 13 \%$ for long elbow bends and showed great discrepancy with a peak error of $-50 \%$ for short elbow bends. The model is reliably acceptable for the elbow bends with relative radius (R/D) greater than 2 at volumetric gas fractions less than 0.3 .
\end{abstract}

Key words: Generalized combined model; two-phase flow; pressure drop; elbow bends

Multi-phase flows are widely encountered in several engineering and industrial facilities such as conventional steam power plants, evaporators and condensers, pressurized-water nuclear reactors, a wide variety of petroleum industries, chemicals and food processing industries. Piping systems in these steam power plants, chemical plants, refineries, oil and gas transportation grids are a very wide and complex. Pipes have to be laid out according to many geometrical and physical constraints. In these piping systems, elbows and bends, expenders and reducers, tee-junctions and control valves are a very common occurrence. In this point, the knowledge of two-phase flow pressure drop in piping components apart from straight pipes is very important for accurate and reliable piping design. It enables the designer to size the pump that is reliable and economic for the operation of the flow system.
On account of two different velocities, two different densities and very complicated flow phenomenon in elbow bends, theory for two-phase flow pressure drop in elbow bends is very rear to be found. Therefore, estimating two-phase flow pressure drop in elbow bends is numerically not an easy task. Even in a single phase flow, there is no exact solution for pressure drop in elbow bends because of the complicated flow phenomena. Nowadays, a few of researchers are trying to develop empirical formula for two-phase flow pressure drop in elbow bends based on experimental data. Benard (2006) developed a correlation for twophase flow pressure drop in elbow by using his experimental data, but his correlation is limited only for $\mathrm{R} / \mathrm{D}=0.6539, \mathrm{Re}_{\mathrm{SL}}=280-9800$ and $\mathrm{Re}_{\mathrm{SG}}=2000-30000$. Seungjin Kima (2008) calculated total losses coefficients $\mathrm{K}$ from experimental pressure drop for $45^{\circ}$ and $90^{\circ}$

\footnotetext{
${ }^{1}$ Department of Mechanical Engineering, Mandalay Technology University, Myanmar

${ }^{2}$ Laboratory of Fluid Mechanics, Department of Mechanical Engineering, Institute Technology Sepuluh Nopember, Campus ITS, Sukolilo, Surabaya

*Corresponding author (e-mail: nay1572@gmail.com)
} 
elbows. Unfortunately their calculation so far has not been satisfactory.

Thus, the objective of this work is to develop a general model that can be used for estimating two-phase flow pressure drops in a wide range of elbow dimensions.

\section{SINGLE PHASE PRESSURE DROP IN ELBOW BENDS}

For a single phase flow, the energy loss through a pipe fitting arising from internal friction, flow separation and secondary flow it is approximately proportional to the square of the flow velocity. Thus, prediction of pressure drop in various pipe fittings (including elbow bends) is not an easy work and most of data on flow through such things are obtained by carefully conducted experiments. In turn, correlating with experimental data, some acceptable formulas have been developed and commercially used to predict pressure drop in piping system designs. In this section, three methods for calculating pressure drop in bends are presented and one of them is proposed for two-phase flow. Generally, for single phase flow, pressure drop in elbow bends is a combination of three components as shown below:

$$
\Delta \mathrm{P}=\Delta \mathrm{P}_{\text {res }}+\Delta \mathrm{P}_{\mathrm{f}}+\Delta \mathrm{P}_{\mathrm{s}} \sin (\gamma)
$$

If the elbow is horizontal, there is no static pressure losses, and so $\Delta \mathrm{P}_{\mathrm{s}}=0$

$$
\begin{aligned}
& \Delta \mathrm{P}=\Delta \mathrm{P}_{\text {res }}+\Delta \mathrm{P}_{\mathrm{f}} \\
& \Delta \mathrm{P}=\left(\mathrm{k}_{\text {res }}+\mathrm{f} \frac{\pi \mathrm{R}}{2 \mathrm{D}}\right) \times \rho \frac{\mathrm{V}_{\text {avg }}^{2}}{2} \\
& \Delta \mathrm{P}=\mathrm{K} \times \rho \frac{\mathrm{V}_{\text {avg }}^{2}}{2} \\
& \left(\text { Where, } \mathrm{K}=\mathrm{k}_{\text {res }}+\mathrm{f} \frac{\pi \mathrm{R}}{2 \mathrm{D}}\right)
\end{aligned}
$$

\section{Total Losses Coefficient Method}

In this method, total losses coefficient $\mathrm{K}$ is defined as combination of restricted loss and frictional loss. The relation of restriction coefficient $\left(\mathrm{k}_{\mathrm{res}}\right)$ and relative radius $(\mathrm{R} / \mathrm{D})$ for various elbow bends is shown in Figure 1.

$$
\mathrm{K}=\mathrm{k}_{\mathrm{res}}+\mathrm{f} \frac{\pi \mathrm{R}}{2 \mathrm{D}}
$$

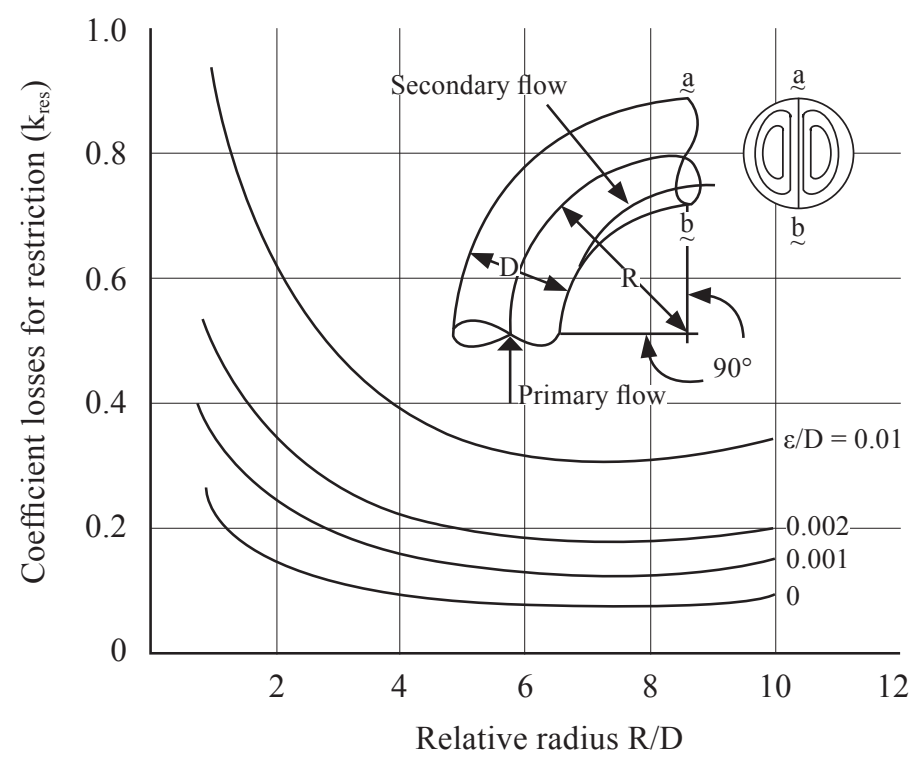

Figure 1. Coefficient losses ( $\left.k_{\text {res }}\right)$ for restriction at various $R / D$. 


\section{Equivalent Length Method}

In this method, total losses coefficient $\mathrm{K}$ is defined as in term of equivalent length.

$$
K=f \frac{L_{e}}{D}
$$

\section{Total Losses Coefficient Method Based on Turbulent Friction Factor}

In fully developed turbulent flow, total losses coefficient is twelve times the turbulent friction factor and it can be calculated by using Colebrook equation for friction factor.

$$
\begin{aligned}
\mathrm{K} & =12 \mathrm{f}_{\mathrm{T}} \\
\mathrm{f}_{\mathrm{T}} & =f(\operatorname{Re}, \kappa / \mathrm{D}) \\
\frac{1}{\sqrt{\mathrm{f}_{\mathrm{T}}}} & =-4 \log \left(\frac{2 \kappa}{\mathrm{D}}+\frac{9.35}{\operatorname{Re} \sqrt{\mathrm{f}_{\mathrm{T}}}}\right)+3.48
\end{aligned}
$$

\section{LOCKHART-MARTINELLI CORRELATION FOR TWO-PHASE FLOW PRESSURE DROP}

The Lockhart-Martinelli (Lockhart \& Martinelli 1949) correlation is perhaps the oldest available correlation for two-phase frictional pressure drop in horizontal pipes. It is widely used in the process industry. It is very simple to apply because it is independent of flow pattern. No liquid fraction information is needed to compute the frictional pressure gradient. It is calculated by multiplying the frictional pressure gradient for single-phase flow (either liquid or gas) by a two-phase flow multiplier $\Phi_{\mathrm{L}}^{2}$ or $\Phi_{\mathrm{G}}^{2}$.

$$
-\frac{d p}{d x}=\Phi_{L}^{2}\left(-\frac{d p}{d x}\right)_{S L, f}=\Phi_{G}^{2}\left(-\frac{d p}{d x}\right)_{S G, f}
$$

$$
\left(-\frac{\mathrm{dp}}{\mathrm{dx}}\right)_{\mathrm{SL}, \mathrm{f}}=2 \mathrm{f}_{\mathrm{SL}} \rho_{\mathrm{L}} \mathrm{U}_{\mathrm{SL}}^{2} / \mathrm{D}
$$

$$
\left(-\frac{\mathrm{dp}}{\mathrm{dx}}\right)_{\mathrm{SG}, \mathrm{f}}=2 \mathrm{f}_{\mathrm{SG}} \rho_{\mathrm{G}} \mathrm{U}_{\mathrm{SG}}^{2} / \mathrm{D}
$$

Here, superficial velocities, $\mathrm{U}_{\mathrm{SL}}$ and $\mathrm{U}_{\mathrm{SG}}$ are expressed as:

$$
\begin{gathered}
\mathrm{U}_{\mathrm{SL}}=\frac{\mathrm{Q}_{\mathrm{L}}}{\mathrm{A}} \\
\mathrm{U}_{\mathrm{SG}}=\frac{\mathrm{Q}_{\mathrm{G}}}{\mathrm{A}}
\end{gathered}
$$

The friction factor for each phase can be calculated by using Colebrook equation. The parameter X, known as the Lockhart-Martinelli parameter which is correlated to the two-phase multipliers will be introduced as,

$$
\begin{array}{r}
X=\left[\begin{array}{c}
\left(-\frac{d p}{d x}\right)_{S L, f} \\
\left(-\frac{d p}{d x}\right)_{S G, f}
\end{array}\right]^{1 / 2} \\
\Phi_{G}^{2}=1+C X+X^{2} \\
\Phi_{L}^{2}=1+\frac{C}{X}+\frac{1}{X^{2}}
\end{array}
$$

Chisholm (1967) introduced a convenient expression for the two-phase multipliers with the following $\mathrm{C}$ values for different types of flow.

Table 1. C values in two-phase multiplier (Chisholm 1967).

\begin{tabular}{c|cc}
\hline Liquid & Gas & C \\
\hline Turbulent & Turbulent & 20 \\
Laminar & Turbulent & 12 \\
Turbulent & Laminar & 10 \\
Laminar & Laminar & 5 \\
\hline
\end{tabular}


The gas fraction needed for the pressure gradient contribution due to gravity is also determined by a correlation developed by Lockhart and Martinelli:

$$
\alpha_{\mathrm{G}}=\left[1+0.28\left(\frac{1-\mathrm{x}}{\mathrm{x}}\right)^{0.64}\left(\frac{\rho_{\mathrm{G}}}{\rho_{\mathrm{L}}}\right)^{0.36}\left(\frac{\mu_{\mathrm{L}}}{\mu_{\mathrm{G}}}\right)^{0.07}\right]^{-1}
$$

Therefore, the static pressure losses are:

$$
\frac{\mathrm{dp}}{\mathrm{dx}}=\mathrm{g} \times\left[\rho_{\mathrm{L}} \alpha_{\mathrm{L}}+\rho_{\mathrm{G}}\left(1 \alpha_{\mathrm{L}}\right)\right]
$$

To be general, if there was any inclination angle $\gamma$ from horizontal, it could be:

$$
\frac{d p}{d x}=g \times\left[\rho_{L} \alpha_{L}+\rho_{G}\left(1 \alpha_{L}\right)\right] \times \sin (\gamma)
$$

\section{DEVELOPING GENERALIZED COMBINED MODEL FOR GAS-LIQUID TWO-PHASE FLOW PRESSURE DROP IN ELBOW BEND}

In this section, a generalized model was proposed for a two-phase flow pressure drop in elbow bends with reasonable considerations so that it could be used in a wide range of conditions. The total losses coefficient method was used in developing the model. The following equation could be written for the two-phase flow pressure drop in elbow bend by using Equation 1:

$$
\begin{aligned}
\Delta \mathrm{P}_{\mathrm{EB}}= & \Delta \mathrm{P}_{\text {res, Two-phase }}+\Delta \mathrm{P}_{\mathrm{f}, \text { Two-phase }} \\
& +\Delta \mathrm{P}_{\mathrm{s}, \text { Two-phase }} \sin (\gamma)
\end{aligned}
$$

Here, first we will consider the two-phase frictional pressure drop, $\Delta \mathrm{P}_{\mathrm{f} \text {, Two-phase }}$ and static

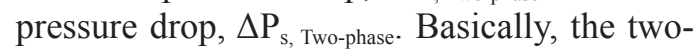
phase flow pressure drop is strongly dependent on phase fraction and the flow pattern. However, in elbow bend it was very difficult to define the flow pattern because of interferences such as separation and secondary flow. Therefore, to solve this problem, Lockhart_Martinelli Correlation was chosen which does not depend on the flow pattern.
The second problem was how to solve the two-phase flow pressure drop because of elbow restriction. According to the momentum theory $(\rho \mathrm{VV})$, if the flowing fluids pass any restriction, fluids with higher densities would suffer from higher momentum losses than lower density fluids. Therefore, if we consider gas-liquid two-phase flow in any elbow bend, momentum losses contributed from liquid phase is nearly the same momentum losses for the whole mixture. As the gas phase density was very low compared with liquid phase, losses contributed from gas phase could be neglected in low gas concentration. But at high gas velocities or high gas concentrations, restriction losses for gas would be considerable as a factor that had to be accounted. Therefore, for low gas concentration it could be written as:

$$
\begin{aligned}
& \Delta \mathrm{P}_{\text {res, Two-phase }}=\mathrm{k}_{\text {res }} \rho_{\mathrm{L}} \frac{\mathrm{U}_{\mathrm{SL}}^{2}}{2} \\
& \Delta \mathrm{P}_{\mathrm{f}, \text { Two-phase }}=\frac{\mathrm{dp}}{\mathrm{dx}} \times \frac{\pi \mathrm{R}}{2} \\
& \Delta \mathrm{P}_{\mathrm{s}, \text { Two-phase }}=\frac{\mathrm{dp}}{\mathrm{dz}} \times \mathrm{R} \times \sin (\gamma)
\end{aligned}
$$


By combining the above three expressions:

$$
\begin{aligned}
\Delta \mathrm{P}_{\mathrm{EB}}= & \mathrm{k}_{\mathrm{res}} \rho_{\mathrm{L}} \frac{\mathrm{U}_{\mathrm{SL}}^{2}}{2}+\left(\frac{\mathrm{dp}}{\mathrm{dx}} \times \frac{\pi \mathrm{R}}{2}\right)+ \\
& \left(\frac{\mathrm{dp}}{\mathrm{dz}} \times \mathrm{R} \times \sin (\gamma)\right)
\end{aligned}
$$

Then, we considered for the case in which the dispersed density became nearly the same with continuous phase density (liquid-liquid flow, oil-water flow). In such a case, the assumption that as homogeneous flow was very reasonable and the mixture possessed average properties of the phases involved. The mixture could be assumed as a single fluid with average properties. The restriction losses, frictional losses and static losses would be contributed from both fluids. Therefore for the two-phase flow in which $\rho_{\mathrm{DL}} \approx \rho_{\mathrm{L}}$ and $\mu_{\mathrm{DL}} \approx \mu_{\mathrm{L}}$, the pressure drop in elbow bends could be developed as follow:

$$
\begin{gathered}
\Delta \mathrm{P}_{\text {res, Two-phase }}=\mathrm{k}_{\text {res }} \rho_{\text {mix }} \frac{\mathrm{U}_{\text {mix }}^{2}}{2} \\
\Delta \mathrm{P}_{\mathrm{f}, \text { Two-phase }}=\mathrm{f}_{\text {mix }} \frac{\pi \mathrm{R}}{2 \mathrm{D}} \frac{\mathrm{U}_{\text {mix }}^{2}}{2} \\
\Delta \mathrm{P}_{\mathrm{s}, \text { Two-phase }}=\rho_{\text {mix }} \times \mathrm{g} \times \mathrm{R} \times \sin (\gamma)
\end{gathered}
$$

By combining the above three expressions:

$$
\begin{gathered}
\Delta \mathrm{P}_{\mathrm{EB}}=\mathrm{k}_{\text {res }} \rho_{\text {mix }} \frac{\mathrm{U}_{\text {mix }}^{2}}{2}+\mathrm{f}_{\text {mix }} \frac{\pi \mathrm{R}}{2 \mathrm{D}} \frac{\mathrm{U}_{\text {mix }}^{2}}{2}+ \\
\rho_{\text {mix }} \mathrm{g} \mathrm{R} \sin (\gamma) \\
\mathrm{U}_{\text {mix }}=\mathrm{U}_{\mathrm{SL}}+\mathrm{U}_{\mathrm{SDL}} \\
\mathrm{U}_{\mathrm{SDL}}=\frac{\mathrm{Q}_{\mathrm{DL}}}{\mathrm{A}} \\
\rho_{\text {mix }}=\rho_{\mathrm{L}}(1-\beta)+\rho_{\mathrm{DL}} \beta \\
\mu_{\text {mix }}=\mu_{\mathrm{L}}(1-\beta)+\mu_{\mathrm{DL}} \beta
\end{gathered}
$$

$$
\begin{gathered}
\operatorname{Re}_{\text {mix }}=\frac{\rho_{\text {mix }} \mathrm{DU}_{\text {mix }}}{\mu_{\text {mix }}} \\
\beta=\frac{Q_{D L}}{Q_{D L}+Q_{L}}=\frac{U_{\text {SDL }}}{U_{\text {mix }}}
\end{gathered}
$$

Here, $\mathrm{f}_{\text {mix }}$ could be calculated by using Equation 8 and mixture Reynolds number.

\section{AVAILABLE EXPERIMENTAL DATA}

Aung (2009) and Sukmono (2009) performed experiments with gas-liquid two-phase flow through elbow bends to investigate gas-liquid two-phase flow pattern and pressure drop characteristics through a vertical to horizontal $90^{\circ}$ elbows. The first conducted tests for elbow bend having (center bend radius to diameter ratio) $\mathrm{R} / \mathrm{D}=2.5$ and the later for $\mathrm{R} / \mathrm{D}=0.6$. For every elbow bend, forty different flow conditions were created by varying inlet superficial liquid velocity $\left(\mathrm{U}_{\mathrm{SL}}=0.3 \sim 1.1 \mathrm{~m} / \mathrm{s}\right)$ and volumetric gas quality $(\beta=0.05 \sim 0.2)$. The test section had $2 \mathrm{~m}$ high vertical pipe and $1 \mathrm{~m}$ long horizontal pipe which was connected with selected elbow. All parts of test section were made of acrylic pipe. A water-filled manometer set was used to measure pressure gradients along test section. The detail of the experimental setup and measuring techniques could be seen in corresponding references. These measured data in experiments were used in validation of estimated data from proposed model.

\section{PREDICTION WITH PROPOSED MODEL AND ERROR ANALYSIS}

Table 1 and 2 summarize the properties of fluids used in experiments and restriction coefficients for elbow bends. These are required data for predictions with the proposed model. The flow diagram for tasks in prediction is shown in Figure 2 and the prediction calculations would be served by using MATLAB as computational tool. 
Table 1. Restriction coefficient for elbow bends.

\begin{tabular}{l|cc}
\hline \multicolumn{1}{c|}{ Parameter } & Long elbow & Short elbow \\
\hline Relative radius (R/D) & 2.5 & 0.6 \\
Diameter [D (m)] & 0.036 & 0.036 \\
Radius of curvature [R (m)] & 0.09 & 0.0216 \\
Restriction coefficient for elbow bends $\left(\mathrm{k}_{\mathrm{res}}\right)$ & 0.156 & 0.35 \\
\hline
\end{tabular}

Table 2. Properties of fluids used in experiments and predictions.

\begin{tabular}{l|cc}
\hline \multicolumn{1}{c|}{ Fluids } & Water & Air \\
\hline Density $\left[\rho\left(\mathrm{kg} / \mathrm{m}^{3}\right)\right]$ & 997 & 1.17 \\
Viscosity $\left[\mu\left(\mathrm{Ns} / \mathrm{m}^{2}\right)\right]$ & 0.00089 & 0.0000181 \\
\hline
\end{tabular}

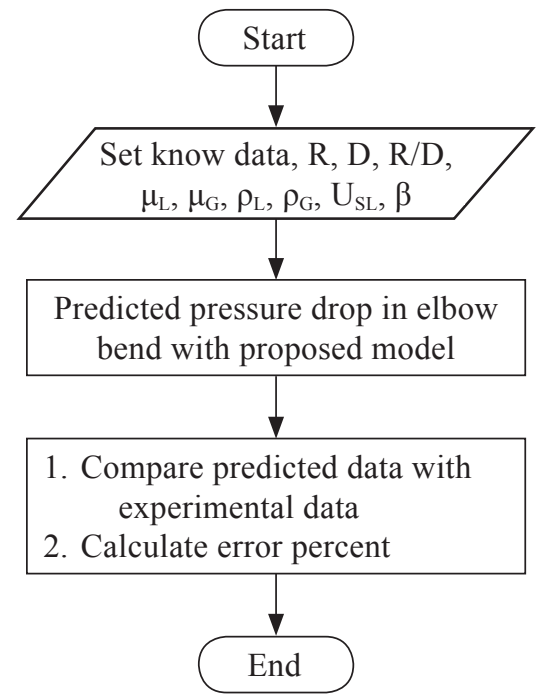

Figure 2. Flow diagram for tasks in prediction.

The validity of the developed model is defined based on definition that corresponds to the minimum root mean square (rms) error. The error $(\varepsilon)$ from applying the model to each available data point is defined as:

$\varepsilon(\%)=\left|\frac{\text { Predicted }- \text { Experimental }}{\text { Experimental }}\right| \times 100$
For groups of data, the root mean square error, $\varepsilon_{\text {rms }}$, is defined as:

$$
\varepsilon_{\mathrm{rms}}(\%)=\left[\frac{1}{\mathrm{~N}} \sum_{\mathrm{i}=1}^{\mathrm{N}} \varepsilon_{\mathrm{i}}^{2}\right]^{1 / 2}
$$

\section{RESULT AND DISCUSSION}

A typical photo of a two-phase flow phenomenon in elbow bend recorded in experiment is shown in Figure 3. It will not be dealt with here, but just for seeing how it behaves. The characteristics of pressure drop in elbow bend were related with observed flow behaviour in it. In general, the results showed that pressure drop characteristics in elbow bends had decreasing trends since elevational pressure drop was the most dominant component in vertical positioned elbow which decreased with increasing amount of gas. However, the frictional and restriction pressure drop become more dominant at high velocities.

Table 3 exhibits comparisons of experimental data and predicted data calculated from proposed method for every constant superficial liquid Reynolds number and Figure 4 shows graphical presentation for $\mathrm{Re}_{\mathrm{SL}}=13497$. 


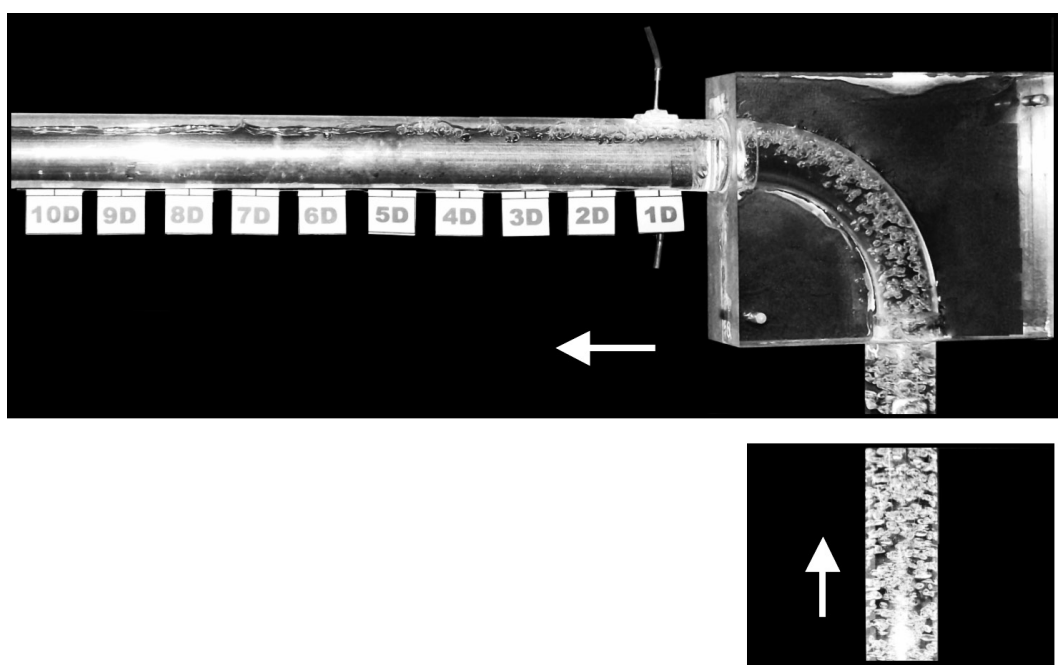

Figure 3. Visual observation of two-phase flow pattern across the elbow at $\operatorname{Re}_{S L}=13497, \alpha=0.07$.

Generally, the proposed method could give estimated data which have the same trend with experimental data. It gives good predictions for long elbow bend (Nay's data) with root mean square error of $2.1 \%$. For short elbow
(Yudi's data), there is a great difference between predicted data and experimental ones until it shows rms of as large as $46 \%$. This discrepancy can be explained by the pressure drop due to restriction and friction. In real two-phase flow in

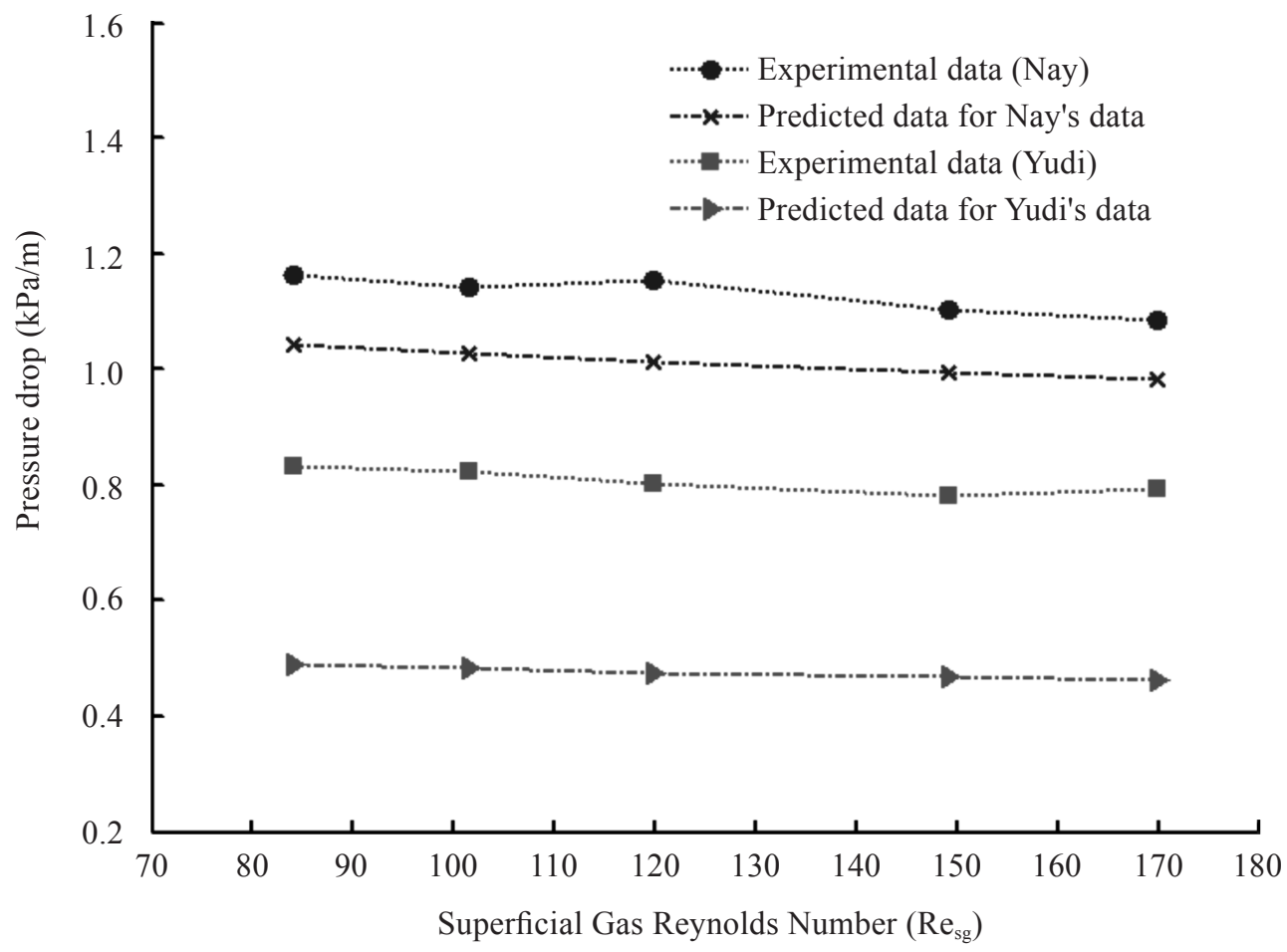

Figure 4. Pressure drop in elbow bends for $R_{S L}=13497$. 
Table 3. Comparison of experimental data and predicted data.

\begin{tabular}{|c|c|c|c|c|c|}
\hline \multirow[b]{2}{*}{$\mathrm{U}_{\mathrm{SL}}(\mathrm{m} / \mathrm{s})$} & \multirow[b]{2}{*}{$\beta$} & \multicolumn{2}{|c|}{ Yudi's data } & \multicolumn{2}{|c|}{ Nay's data } \\
\hline & & $\begin{array}{c}\text { Experimental } \\
\text { Pressure drop }\left(\mathrm{N} / \mathrm{m}^{2}\right)\end{array}$ & $\begin{array}{l}\text { Predicted data } \\
\qquad\left(\mathrm{N} / \mathrm{m}^{2}\right)\end{array}$ & $\begin{array}{c}\text { Experimental } \\
\text { Pressure drop }\left(\mathrm{N} / \mathrm{m}^{2}\right)\end{array}$ & $\begin{array}{l}\text { Predicted data } \\
\qquad\left(\mathrm{N} / \mathrm{m}^{2}\right)\end{array}$ \\
\hline \multirow[t]{5}{*}{0.3} & 0.11 & 831.35 & 528.26 & 1162.72 & 1126.47 \\
\hline & 0.13 & 821.57 & 522.03 & 1143.18 & 1112.84 \\
\hline & 0.15 & 802.01 & 516.04 & 1152.95 & 1099.71 \\
\hline & 0.18 & 782.45 & 507.33 & 1104.10 & 1080.64 \\
\hline & 0.20 & 792.23 & 501.77 & 1084.55 & 1068.46 \\
\hline \multirow[t]{7}{*}{0.5} & 0.07 & 948.72 & 576.80 & 1221.30 & 1181.32 \\
\hline & 0.09 & 899.81 & 569.74 & 1201.80 & 1165.83 \\
\hline & 0.11 & 890.03 & 563.23 & 1172.50 & 1151.57 \\
\hline & 0.13 & 880.25 & 557.06 & 1182.30 & 1138.03 \\
\hline & 0.15 & 831.35 & 551.14 & 1123.60 & 1125.06 \\
\hline & 0.18 & 802.01 & 542.58 & 1113.90 & 1106.29 \\
\hline & 0.20 & 831.35 & 537.08 & 1104.10 & 1094.24 \\
\hline \multirow[t]{8}{*}{0.7} & 0.05 & 1173.67 & 635.66 & 1240.90 & 1233.24 \\
\hline & 0.07 & 1173.67 & 628.03 & 1221.30 & 1216.47 \\
\hline & 0.09 & 1144.33 & 621.14 & 1192.00 & 1201.35 \\
\hline & 0.11 & 1124.77 & 614.71 & 1182.30 & 1187.23 \\
\hline & 0.13 & 1075.86 & 608.55 & 1162.70 & 1173.72 \\
\hline & 0.15 & 1026.96 & 602.80 & 1143.20 & 1161.09 \\
\hline & 0.18 & 997.62 & 594.38 & 1104.10 & 1142.61 \\
\hline & 0.20 & 1007.40 & 588.97 & 1094.30 & 1130.73 \\
\hline \multirow[t]{8}{*}{0.9} & 0.05 & 1359.50 & 703.07 & 1280.00 & 1278.32 \\
\hline & 0.07 & 1369.28 & 695.63 & 1280.00 & 1261.95 \\
\hline & 0.09 & 1427.96 & 688.85 & 1250.70 & 1247.03 \\
\hline & 0.11 & 1330.16 & 682.54 & 1211.60 & 1233.17 \\
\hline & 0.13 & 1261.69 & 676.56 & 1201.80 & 1220.01 \\
\hline & 0.15 & 1232.35 & 670.84 & 1172.50 & 1207.45 \\
\hline & 0.18 & 1203.01 & 662.59 & 1182.26 & 1189.30 \\
\hline & 0.20 & 1212.79 & 657.27 & 1182.30 & 1177.60 \\
\hline \multirow[t]{8}{*}{1.1} & 0.05 & 1760.50 & 786.76 & 1348.40 & 1333.51 \\
\hline & 0.07 & 1799.62 & 779.44 & 1348.40 & 1317.40 \\
\hline & 0.09 & 1770.28 & 772.81 & 1289.70 & 1302.78 \\
\hline & 0.11 & 1828.97 & 766.62 & 1299.50 & 1289.15 \\
\hline & 0.13 & 1760.50 & 760.77 & 1309.30 & 1276.26 \\
\hline & 0.15 & 1740.94 & 755.17 & 1280.00 & 1263.93 \\
\hline & 0.18 & 1604.01 & 747.09 & 1250.70 & 1246.13 \\
\hline & 0.20 & 1594.23 & 741.88 & 1280.00 & 1234.65 \\
\hline
\end{tabular}


very short elbow, the turbulence is enhanced by gas bubbles that cause an increase in frictional and restricting pressure drop. Therefore, the experimental pressure drops greatly to overcome the predicted data.

The other observation is that at higher liquid velocities, the pressure drop in the short elbow is much higher than that in the long elbow bend. Thus, the higher the gas velocity, the bigger is the error for the proposed model. It is noteworthy that predictions by the proposed model is appropriate for long elbows while it is quite poor for short elbows. Figures 5-6 depict the direct comparison of the whole predictive data to the experimental database for both elbows. It can be seen that this proposed method is weak in estimating pressure drop for $\mathrm{R} / \mathrm{D}=0.6$ with maximum error greater than $-50 \%$. However, most of predicted data fall within the error limits of $\pm 13 \%$ for $R / D=2.5$.

\section{CONCLUSION}

From this work, a general combined model to predict two-phase flow pressure drop in elbow bends was developed. In the model, restriction pressure drop, frictional pressure drop and elevational pressure drop were considered separately. Lockhart_Martinelli Correlaiton was borrowed to predict the frictional and elevational pressure drop. It was tested to predict the experimental data for two types of elbow bends with $\mathrm{R} / \mathrm{D}=0.6$ and $\mathrm{R} / \mathrm{D}=2.5$. The results showed that the proposed model well predicted pressure drop for long elbow $(\mathrm{R} / \mathrm{D}=2.5)$ with maximum error of $\pm 13 \%$ and $\varepsilon_{\mathrm{rms}}$ of $2.1 \%$, meanwhile it had poor predictions for short elbow $(\mathrm{R} / \mathrm{D}=0.6)$ which gave a maximum error higher than $-50 \%$ and $\varepsilon_{\text {rms }}$ of $46 \%$. However, it was appropriate for all experimental data. As discussed earlier, this model could be proposed for future studies on two phase flow in the long elbows with a

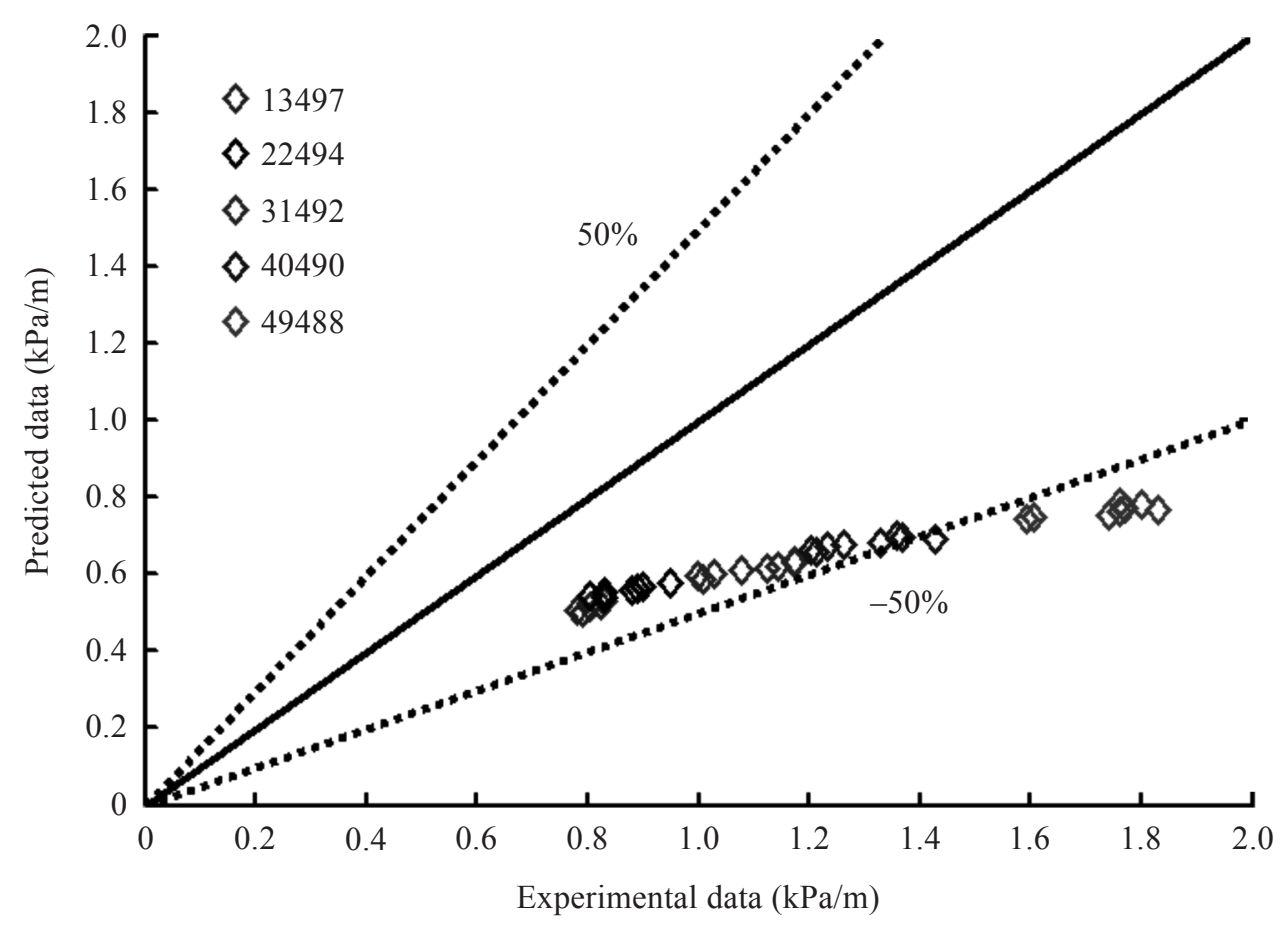

Figure 5. Experimental pressure drops against predicted pressure drops in elbow bend with $R / D=0.6$. 


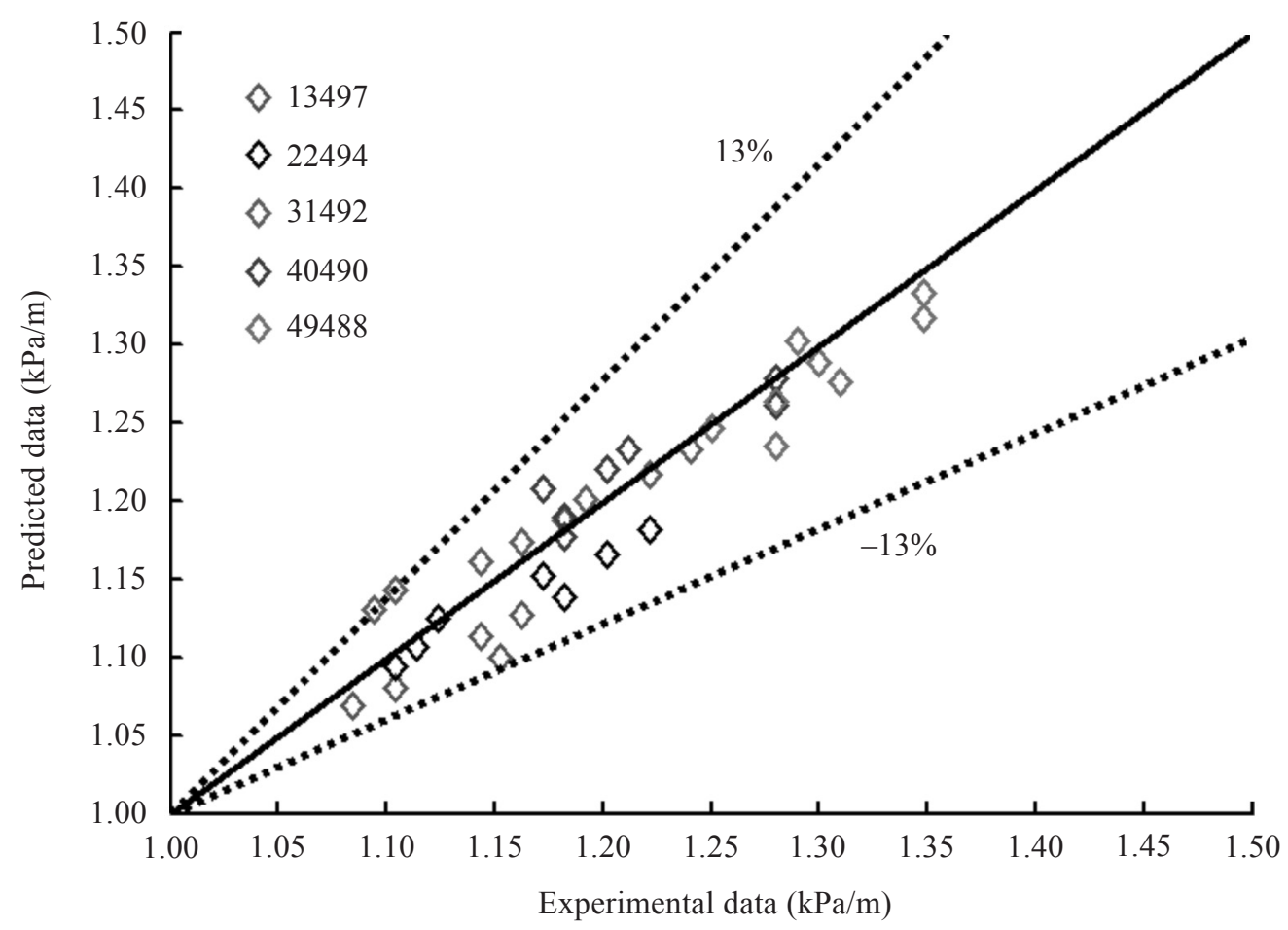

Figure 6. Experimental pressure drops against predicted pressure drops in elbow bend with $R / D=2.5$.

relative radius greater than 2 and volumetric gas quality not higher than 0.3 . But a higher value of $\mathrm{k}_{\mathrm{res}}$ could be considered in the short elbow bends.

\section{Date of submission: June 2012}

Date of acceptance: October 2012

\section{ACKNOWLEDGEMENT}

The author would like to express his special thanks to his supervisor and advisor Prof.Dr. Triyogi Yuwono, DEA for his valuable advice, patience, understanding and educational challences throughout the duration of this research and all the staff of the Fluid Mechanic Lab, Mesin, ITS for the facility support and valuable assistance.

\section{REFERENCES}

Angeli, P 2006, 'Upward and downward inclination oil-water flow', International Journal of Multiphase Flow, vol. 32, pp. 413-435.

Aung, NZ 2009, 'Experimental and numerical investigation of gas-liquid two phase flow characteristics after vertical to horizontal $90^{\circ}$ elbow (case study for $\mathrm{R} / \mathrm{D}=2.5$ )', Thesis, Department of Mechanical Engineering, Institute Technology Sepuluh Nopember.

Benard, E 2006, 'Gas-liquid two phase flow through a vertical $90^{\circ}$ elbow bend', Experimental Thermal and Fluid Science, vol. 31, pp. 761-769.

Crowe, CT 2006, Multiphase flow handbook, Taylor \& Francis Group, New York.

Guo, B et al. 2005, Offshore pipelines, University of Louisiana at Lafayette. 
Kima, S 2007, 'Geometric Effects of 90-degree elbow in the development of interfacial structures in horizontal bubbly flow', Nuclear Engineering and Design, vol. 237, pp. 2105-2113.

Levy, EK 2000, 'Gas-solid flow behavior in a horizontal pipe after a $90^{\circ}$ vertical-to-horizontal elbow', Powder Technology, vol. 116, pp. 43-52.

Sukmono, Y 2009, 'Experimental and numerical investigation of gas-liquid two phase flow characteristics after vertical to horizontal $90^{\circ}$ elbow (case study for $\mathrm{R} / \mathrm{D}=0.6$ )', Thesis, Department of Mechanical Engineering, Institute Technology Sepuluh Nopember.

Wang, CC 2002, 'Influence of horizontal return bend on the two-phase flow pattern in small diameter tubes', Experimental Thermal and Fluid Science, vol. 28, pp. 145-152.

\section{NOMENCLATURE}

\section{Notation}

D Diameter of the pipe (m)

$\mathrm{dp} / \mathrm{dx} \quad$ Pressure gradient with vitiation of pipe length $(\mathrm{Pa} / \mathrm{m})$

$\mathrm{dp} / \mathrm{dz} \quad$ Pressure gradient with lavational variation $(\mathrm{Pa} / \mathrm{m})$

f Fanning friction factor

g Acceleration due to gravity $\left(\mathrm{m} / \mathrm{s}^{2}\right)$

K Total losses coefficient

$\mathrm{k} \quad$ Restriction coefficient

L Length (m)

$\mathrm{P} \quad$ Toal pressure $(\mathrm{kPa})$

Q Flow rate $\left(\mathrm{m}^{3} / \mathrm{s}\right)$

$\mathrm{R} \quad$ Radius of curvature (m)

Re Reynolds number

U Superficial velocity respective phase $(\mathrm{m} / \mathrm{s})$

$\mathrm{V} \quad$ Velocity of single phase flow $(\mathrm{m} / \mathrm{s})$

$\mathrm{x} \quad$ Mass quality of gas

\section{Symbols}

$\alpha \quad$ Fraction of respective phase

$\beta \quad$ Fraction of respective phase in homogenous flow

$\gamma \quad$ Elbow inclination angle (degree)

$\rho \quad$ Density $\left(\mathrm{kg} / \mathrm{m}^{3}\right)$

$\mu \quad$ Viscosity $(\mathrm{N}-\mathrm{s} / \mathrm{m})$

$\kappa \quad$ Pipe surface roughness (m)

\section{Subscript}

EB

$\mathrm{f}$

res

$\mathrm{s}$

Two-phase Two-phase flow

mix

$\mathrm{L}$

G

SDL

SG

SL
Elbow

Fractional

Reaction

Static

Mixutre

Liquid

Gas

Superficial dispersed liquid

Superficial gas

Superficial liquid 